\title{
The Relationship Between Sleep Quality and Neck Pain, Shoulder Pain and Disability, Physical Activity, and Health Perception Among Middle-Aged Women : A Cross-Sectional Study
}

Myung Kyung Lee

Kyungpook National University

Jihyun Oh ( $\square$ grape0123@hanmail.net)

Daejeon University

\section{Research Article}

Keywords: sleep quality, shoulder pain, women, health perception

Posted Date: November 30th, 2021

DOI: https://doi.org/10.21203/rs.3.rs-1067975/v1

License: (a) This work is licensed under a Creative Commons Attribution 4.0 International License.

Read Full License 


\section{Abstract \\ Background}

Sleep quality is an important physical requirement for a healthy life, and good sleep quality has been recognized as a significant component in physical and mental health and well-being. The purpose of this study was to identify the factors that affect sleep quality as well as the relationship between sleep quality and neck pain, shoulder pain and disability, physical activity, and health perception.

\section{Methods}

We conducted surveys on 494 women between the age of 35 and 64 years. The study evaluated neck pain, shoulder pain and disability, physical activity, self-health perception and sleep quality with selfreported questionnaires in middle-aged women. Data were analyzed using SPSS 23.0.

\section{Results}

The results showed that the more severe the neck pain and shoulder pain and disability, the worse the sleep quality was in middle-aged women and the better the health perception, the lower the sleep quality score was, indicating good sleep quality. Shoulder pain, self-perceived task difficulty, and health perception were identified as variables that affected the sleep quality in middle-aged women. The explanatory power of the model in explaining sleep quality was $22.9 \%$.

\section{Conclusions}

To improve the sleep quality in middle-aged women, healthcare workers should take into consideration the subjects' symptoms, such as pain, in accordance to their health. Perceived difficulty of one's work and their health can affect sleep quality; hence, it is necessary to develop health intervention strategy to provide health management, emotional support, and social support for the purpose of improving daily sleep quality.

\section{Background}

Chronic neck pain affects $16.7-75.1 \%$ of the world's population annually, and such neck pain is thought to be caused by various factors, including hormonal changes and mechanical and postural overload. ${ }^{1}$ Shoulder pain occurs with a lifetime prevalence of $6.7-66.7 \% .{ }^{2}$ Neck pain, shoulder pain, and shoulder disabilities are the most common illnesses among musculoskeletal disorders that reduce work efficiency as well as work productivity. ${ }^{3,4}$ Workers with a high level of physically demanding work are at a higher risk of developing disabilities than those with a lower level of physically demanding work. ${ }^{5,6}$ Physically 
demanding jobs are more likely to develop work-related neck disorders. ${ }^{6}$ People with neck pain are more prone to getting lower sleep quality than people with no neck pain, and middle-aged women in particular experience discomfort due to female hormonal changes (e.g., menopause) that aggravate sleep disorders that interfere with sleep quality. ${ }^{1,7}$ It was found that neck or shoulder pain and disability can affect the degree of physical exertion at one's current job while also interfering with the sleep quality.

Sleep quality is an important physical requirement for a healthy life, and good sleep quality has been recognized as a significant component in physical and mental health and well-being. ${ }^{8}$ The subjects' sleep quality affects not only their quality of life but also their physical, mental, and social aspects. ${ }^{7,9}$ Therefore, it is expected that examining the factors that affect the sleep quality in middle-aged women will have significant ramifications.

The degree of one's self-perceived health affects sleep quality, ${ }^{10}$ and the degree of one's health perception varies according to the changes in physical function that appears with age and development of chronic illnesses. In middle-aged women, metabolism, estrogen level, and physiological functions all gradually decrease with the onset of menopause. Therefore, from Rosenstock's Health education: Theory, research, and practice ${ }^{11}$ point of view, which emphasizes that one of the ways to control one's illness is to have a fixed belief in one's health, an individual's belief and attitude toward physical and mental illness are important factors in influencing health behaviors. As one of such health behaviors, regular exercise is the easiest behavior to incorporate into daily life. It not only improves physical health but also affects sleep quality, which is important in maintaining a long-lasting healthy life. ${ }^{7,12}$

In previous studies, it was reported that physical activity showed the lowest score of occurrences among health-promoting behaviors ${ }^{13}$ and that working women and elderly women have low sleep quality, ${ }_{1}^{14,15}$ but there are very few studies examining the sleep quality and physical activity among middle-aged women in South Korea. Physical activity is known to maintain women's health, and physical inactivity is an important factor in various chronic diseases such as obesity, diabetes, and cardiovascular diseases. ${ }^{16-18}$ In addition, people who spend long periods of time sitting down or being physically inactive tend to have shorter sleep period or poor sleep quality. ${ }^{12,19,20}$ Based on previous studies, the level of physical activity is an important factor in deciding sleep quality. However, previous studies have shown that there is no correlation between physical activity and sleep quality. ${ }^{21}$ Despite studies that show physical activity can alleviate insomnia symptoms in middle-aged women, ${ }^{22}$ there are studies that show physical activity has no effect in improving sleep quality. Thus, it is important to examine how physical activity affects sleep in middle-aged women in South Korea. Therefore, the purpose of this study was to investigate the effects of neck pain, shoulder pain and disability, physical activity, and health perception on sleep quality in middle-aged women.

\section{Methods}

\section{Design and sample}


This descriptive research study was designed to identify the relationship between sleep quality and neck pain, shoulder pain and disability, physical activity, and health perception and to analyze factors that affect sleep quality. The participants selected for this study were 494 middle-aged women between the age of 35 and 64 years who resided in the city of Seoul. The study was conducted from June 1, 2021 to June 22, 2021. After directly providing sufficient explanation of the questionnaires to the participants, cooperation and consent was obtained as well as the consent for participation in the study. The questionnaires were then distributed, and after having the participants self-report, the completed questionnaires were collected. The time spent to collect the data for each participant was approximately $15 \mathrm{~min}$. Out of the 515 questionnaires distributed and collected through this process, 494 questionnaires were used as the final valid samples, excluding the data that were judged as being incomplete or insincerely answered (Questionnaire response rate: 95.9\%).

\section{Measurement}

\section{Sleep quality}

Sleep quality was assessed using the Pittsburgh Sleep Quality Index (PSQI) developed by Buysse, Reynolds III, Monk, Berman, and Kupfer, ${ }^{23}$ which is a self-report questionnaire scored out of 19 items. The PSQI has seven components: subjective sleep quality, sleep latency, total sleep duration, sleep efficiency, sleep disturbance, use of sleep medication, and daytime dysfunction. It is a tool that has been used extensively for a wide range of populations and shows the severity of several sleep problems. The total PSQI score ranges from 0 to 21 with each of the 7 components scored from 0 to 3 which are then summed to produce the global score. Buysse ${ }^{23}$ defines a score of $\geq 5$ as poor sleep and a score of $<5$ as good sleep. Hence, the seven components of PSQI as well as the total PSQI score indicate that the higher the sleep score, the poorer the sleep quality. As for the tool's reliability, Cronbach's a for this scale was 0.90 in this study.

\section{Shoulder Pain and Disability Index}

The Shoulder Pain and Disability Index (SPADI) is a self-report assessment tool that assesses shoulder pain and disability. This assessment tool has 2 subsections and 13 items in total, with 5 items in the pain subsection and 8 items in the disability subsection. For each of the items in the two subsections, the score ranged from 0 (no pain or difficulty) to 10 (worst pain or disability). ${ }^{24}$ The final score is calculated by summing the total pain score and total disability score with 100 as the full score. A higher score on each of the subsection means more severe the pain or higher level of disability. ${ }^{25}$ The Cronbach's a in this study was 0.96 .

\section{Northwick Park Neck Pain Questionnaire}

The Northwick Park Neck Pain Questionnaire (NPQ) ${ }^{26}$ is a self-report assessment tool that consists of nine daily activity-related items (intensity, sleep, numbness, duration, carrying things, reading/watching television, working, social activities, and driving) that are affected by neck pain. Each item consists of one 
question and five responses that indicate increasing level of difficulty and pain. The patient chooses one response that is the most reflective of their current situation. Each item ranges from a score of 0 to 4 with 4 indicating the worst disability. The total score is the summation of scores from the nine items (range of possible scores: $0-36$ ). In this study, a Korean version of the NPQ translated and verified for reliability and validity by Lee et $\mathrm{al}^{27}$ was used, and the Cronbach's $\otimes$ in the present study was 0.93 .

\section{Health perception}

Health perception refers to the state of an individual's perception that governs their health behavior. ${ }^{28}$ In this study, the scale for measuring general health perception developed by Ware ${ }^{28}$ was translated to suit Koreans, and the assessment tool modified by Lee ${ }^{29}$ was used. This assessment tool has a total of 20 items and consists of current health, prior health, health outlook, health worries and concerns, resistance and susceptibility, and rejection of sick role as components. It is on a 4-point Likert scale, and a higher score indicates a higher subjective health status. The Cronbach's a in the present study was 0.86 .

\section{International Physical Activity Questionnaire}

To measure the subjective physical activity in this study, a Korean version of the International Physical Activity Questionnaire (IPAQ) short form was used, which is an assessment tool used to comprehensively and objectively evaluate daily physical activity. ${ }^{30}$ IPAQ short form assesses the frequency and the average duration per day at which $>10$ min of vigorous physical activity (VPA), moderate physical activity (MPA), walking, and sitting was performed within the frame of last 7 days. In this study, six questions were used to determine the overall average metabolic equivalent (MET) score when calculating the metabolic equivalent unit (Metabolic Equivalent Unit: MET-min/week), excluding the first question which asks about "time spent sitting" (Walking = 3.3 METs, Moderate Physical Activity = 4.0 METs and Vigorous Physical Activity $=8.0 \mathrm{METs}$ ). The amount of physical activity was converted into metabolic equivalent unit according to the IPAQ scoring protocol, and the physical activity of the participants was then categorized into inactive, minimally active or health-enhancing physical activity. "Inactive" is the most minimum amount of physical activity and refers to individuals who do not meet the criteria for either minimally active or health-enhancing physical activity. "Minimally active" category refers to those who meets any of the following criteria: $\geq 3$ days of VPA of at least 20 min per day, $\geq 5$ days of MPA and/or walking of at least 30 min per day, and lastly, $\geq 5$ days of any combination of walking, MPA, and VPA, achieving a minimum total physical activity of $600 \mathrm{MET}$-min/week. "Health-enhancing physical activity" is the most ideal category of physical activity and refers to those who meets either of the following criteria: VPA on at least 3 days in the last 7 days, achieving a minimum of total physical activity of 1,500 MET-min/week or $\geq 7$ days of any combination of walking, MPA or VPA, achieving a minimum of total physical activity of 3,000 MET-min/week.

\section{Ethical considerations}

This study was approved by the Institutional Review Board at the Daejeon University (1040647-202103HR-006-02) to secure research ethics for the participants. The participants provided informed written consent after they were given an explanation about the purpose of the study, their freedom to withdraw 
from the study at any point, the confidentiality of the data collected in accordance to the Personal Information Protection Act, the strict research-only usage of the data collected, anonymization of the data, and the document's safekeeping in a location with a double lock. The copy of the explanations and the consent form was provided to the participants, and the completed questionnaires and consent form were collected and kept in individual files to protect personal information. The research was performed in accordance with the ethical guidelines of the Declaration of Helsinki.

\section{Statistical analyses}

All the data collected was analyzed using SPSS version 23.0 (IBM Corp., Armonk, NY, USA). The participants' general characteristics, neck pain, shoulder pain and disability, physical activity, health perception and sleep quality was calculated using the mean and standard deviation. The difference in sleep quality in accordance with the participants' general characteristics was analyzed using analysis of variance and the post hoc analysis was verified using Sheffé test. The correlation between the participants' neck pain, shoulder pain and disability, physical activity, and health perception and sleep quality was analyzed using Pearson's correlation coefficient. Stepwise multiple regression was used to analyze the degree of effect on the participant's sleep quality.

\section{Results}

\section{Participants' general characteristics and differences}

A total of 494 participants out of 515 were analyzed as the final data, excluding insincere and omitted responses (response rate: $95.9 \%$ ). The average age of the participants was 42.40 (6.51) years and the range was 35-63 years. As for marital status, 357 (72.3\%) participants were married, which was more than half of the participants, and as for education, 400 (81.0\%) participants received a college degree. Regarding drinking and smoking, 479 (97.0\%) participants were nonsmokers and 271 (54.9\%) did not drink alcohol at all; 390 (78.9\%) participants answered that their economic status was "middle" and 320 (64.8\%) participants did not have any comorbidities. Furthermore, 407 (82.4\%) participants had a job and when asked about the degree of difficulty of their work that they perceived, 245 (49.6\%) responded that it was moderate. Lastly, as a result of analyzing the ratio according the level of physical activity, 294 (52.6\%) participants were in inactive, 167 (29.9\%) were minimally active, and 33 (5.9\%) were healthenhancing physical activity active (Table 1 ). 
Table 1

Descriptive statistics ( $N=494)$

\begin{tabular}{|c|c|c|c|c|c|}
\hline \multirow[t]{2}{*}{ Characteristics } & \multirow[t]{2}{*}{$\begin{array}{l}\text { Mean } \\
\text { (SD) }\end{array}$} & \multirow[t]{2}{*}{ Range } & \multirow[t]{2}{*}{ n (\%) } & \multicolumn{2}{|c|}{ PSQI Global Score } \\
\hline & & & & Mean & $\begin{array}{l}\text { tor } F(p) \\
\text { Scheffé }\end{array}$ \\
\hline Age (year) & $\begin{array}{l}42.40 \\
(6.51)\end{array}$ & $\begin{array}{l}35- \\
63\end{array}$ & & & \\
\hline$\geq 39^{a}$ & & & $\begin{array}{l}209 \\
(42.3)\end{array}$ & $9.31(2.63)$ & $4.635(.010)$ \\
\hline$\geq 49^{b}$ & & & $\begin{array}{l}201 \\
(40.7)\end{array}$ & $\begin{array}{l}8.60 \\
(2.74)\end{array}$ & $a>b$ \\
\hline$\leq 50^{c}$ & & & $\begin{array}{l}84 \\
(17.0)\end{array}$ & $\begin{array}{l}8.47 \\
(2.75)\end{array}$ & \\
\hline \multicolumn{6}{|l|}{ Marital status } \\
\hline Single & & & $\begin{array}{l}125 \\
(23.3)\end{array}$ & $\begin{array}{l}8.61 \\
(2.74)\end{array}$ & $1.313(.270)$ \\
\hline Married & & & $\begin{array}{l}357 \\
(72.3)\end{array}$ & $\begin{array}{l}8.94 \\
(2.70)\end{array}$ & \\
\hline Divorced \& Widowed & & & $12(2.4)$ & $\begin{array}{l}9.75 \\
(2.76)\end{array}$ & \\
\hline \multicolumn{6}{|l|}{ Education } \\
\hline$\geq$ Middle school & & & $\begin{array}{l}94 \\
(19.0)\end{array}$ & $\begin{array}{l}9.12 \\
(2.75)\end{array}$ & $0.971(.332)$ \\
\hline College & & & $\begin{array}{l}400 \\
(81.0)\end{array}$ & $\begin{array}{l}8.82 \\
(2.70)\end{array}$ & \\
\hline \multicolumn{6}{|l|}{ Smoking } \\
\hline Yes & & & $15(3.0)$ & $\begin{array}{l}9.40 \\
(2.82)\end{array}$ & $0.748(.455)$ \\
\hline No & & & $\begin{array}{l}479 \\
(97.0)\end{array}$ & $\begin{array}{l}8.86 \\
(2.71)\end{array}$ & \\
\hline \multicolumn{6}{|l|}{ Alcohol } \\
\hline Yes & & & $\begin{array}{l}223 \\
(45.1)\end{array}$ & $\begin{array}{l}9.06 \\
(2.62)\end{array}$ & $1.371(.171)$ \\
\hline No & & & $\begin{array}{l}271 \\
(54.9)\end{array}$ & $\begin{array}{l}8.73 \\
(2.78)\end{array}$ & \\
\hline
\end{tabular}




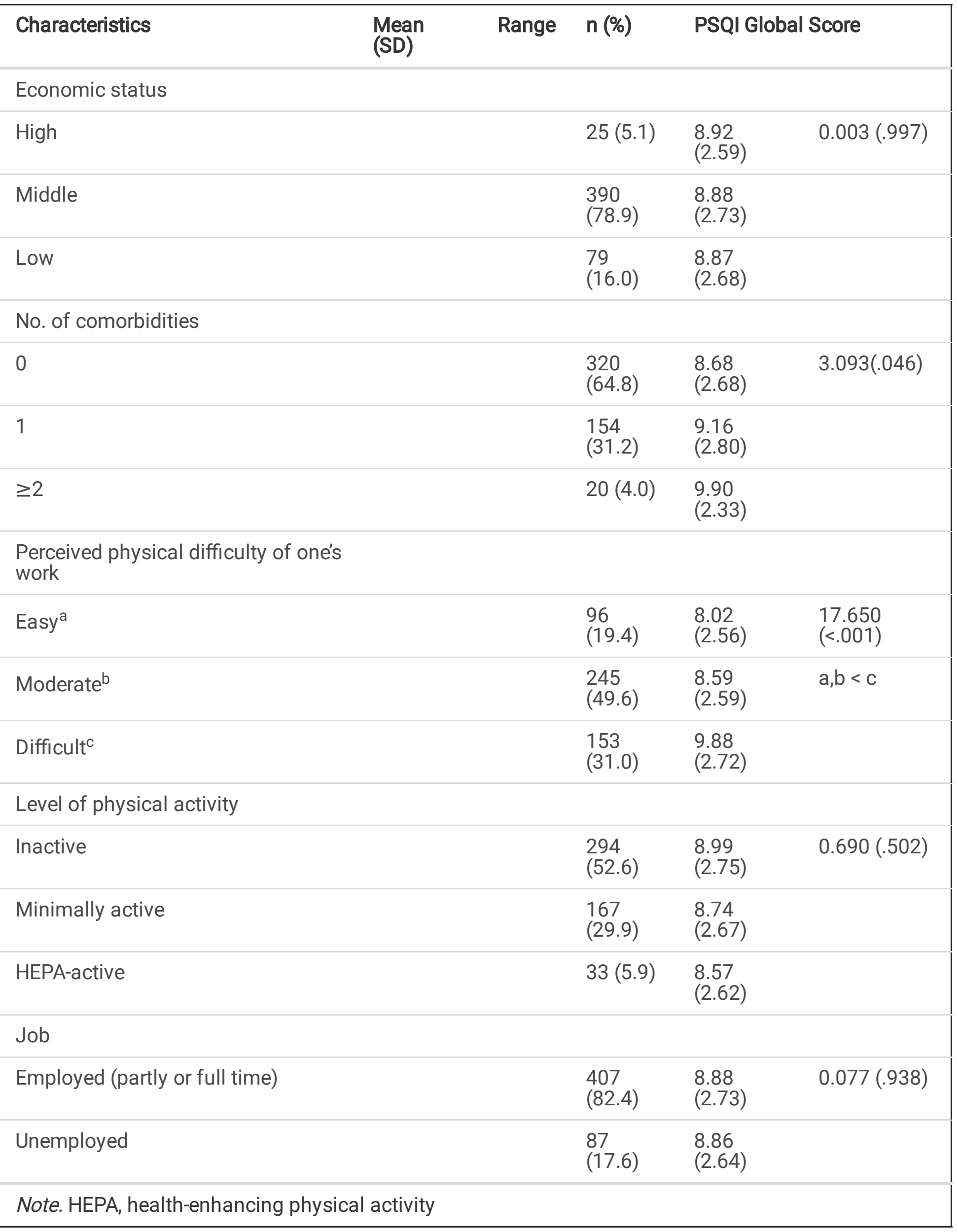


As a result of analyzing the total PSQI score in accordance to general characteristics, there were statistically significant differences depending on the age $(F=4.635, p<0.001)$, number of comorbidities $(F=3.093, p=0.046)$ and perceived physical difficulty of one's work $(F=17.650, p<0.001)$. Regarding the participants' age, post hoc analysis using Scheffé test showed that participants aged 35-39 years had a statistically significant worst sleep quality than those in their 40 s. There was a statistically significant difference in sleep quality according to the number of comorbidities, and those with $\geq 2$ comorbid diseases had the highest sleep quality score than those with none. Post hoc analysis using Scheffé test showed no difference. There was a statistically significant difference in sleep quality according to the perceived physical difficulty of one's work, and a post hoc analysis using Scheffé test showed that participants who said their work was physically difficult had the worst sleep quality.

\section{Scores for NPQ, SPADI, physical activity, health perception, and sleep quality}

As shown in Table 2, the total PSQI average score was 8.88 (2.71), ranging from 2 to 17 points. Within PSQI's components, the average of subjective sleep quality was $1.31(0.63)$, the average of sleep latency was $1.38(0.90)$, the average of sleep duration was $0.47(0.73)$, the average of habitual sleep efficiency was $0.56(0.98)$, the average sleep disturbances were $1.25(0.56)$, the average of sleeping medicine usage was 0.18 (0.59) and the average of daytime dysfunction was 1.24 (0.94). As for sleep quality, the average of poor sleep quality was 9.42 (2.33) and the average of good sleep quality was $4.29(0.87)$. As a result of analyzing the level of physical activity, the total average of the IPAQ was 1723.3 min per week, walking activity was 785.15 min per week, moderate activity was 354.45 min per week, and vigorous activity was 577.00 min per week. As for shoulder pain and disability, the average for shoulder pain was 42.55 (24.72) out of 100points and shoulder disability was 27.29(23.38) out of 100 points. The average of neck pain was 31.51 (19.42) and the average of health perception was 49.27 (7.03). 
Table 2

Level of NPQ, SPADI, IPAQ, and PSQI $(N=494)$

\begin{tabular}{|llll|}
\hline Variables & Min-Max & Mean (SD) & n (\%) \\
\hline Total PSQI score & $2-17$ & $8.88(2.71)$ \\
\hline Subjective sleep quality & $0-3$ & $1.31(0.63)$ \\
\hline Sleep latency & $0-3$ & $1.38(0.90)$ \\
\hline Sleep duration & $0-3$ & $0.47(0.73)$ \\
\hline Habitual sleep efficiency & $0-3$ & $0.56(0.98)$ \\
\hline Sleep disturbances & $0-3$ & $1.27(0.56)$ \\
\hline Use of sleeping medicine & $0-3$ & $0.18(0.59)$ \\
\hline Daytime dysfunction & $0-3$ & $1.24(0.94)$ \\
\hline Good sleep quality & & $4.29(0.87)$ \\
\hline Poor sleep quality & & $9.41(2.33)$ \\
\hline IPAQ score, min/week & $0-39680$ & $1723.30(2824.31)$ \\
\hline Vigorous activity, min/week & $0-26880$ & $577.00(1931.42)$ \\
\hline Moderate activity, min/week & $0-12800$ & $354.45(1056.30)$ \\
\hline Walking activity, min/week & $0-8316$ & $785.15(1049.19)$ \\
\hline SPADI & $0-89.38$ & $33.95(21.90)$ \\
\hline Pain subscale & $0-98$ & $42.55(24.72)$ \\
\hline Disability subscale & $0-100$ & $27.29(23.38)$ \\
\hline NPQ & $0-83.33$ & $31.51(19.42)$ \\
\hline Health perception & $20-76$ & $49.27(7.03)$ \\
\hline Note. NPQ, Northwick Park Neck Pain Questionnaire; SPADI, Shoulder Pain and Disability Index; IPAQ, \\
\hline International Physical Activity Questionnaire;PSQI,Pittsburgh Sleep Quality Index \\
\hline
\end{tabular}

\section{Correlations between NPQ, SPADI, physical activity, health perception, and sleep quality}

The correlation between variables is shown in Table 3. Neck pain had a positive correlation with SPADI's components, pain $(r=0.418, p<0.001)$ and disability $(r=0.404, p<0.001)$, as well as total sleep quality $(r=0.253, p<0.001)$, but showed negative correlation with health perception $(r=-0.326, p<0.001)$. Among SPADI's components, pain showed a positive correlation with disability $(r=0.708, p<0.001)$ and total sleep quality $(r=0.404, p=0.004)$, but showed a negative correlation with health perception $(r=$ 
-0.347, $\mathrm{p}<0.001)$. Among SPADI's components, disability showed a positive correlation with sleep quality $(r=0.301, p<0.001)$ and a negative correlation with health perception $(r=-0.302, p<0.001)$. Moreover, sleep quality and health perception showed a negative correlation $(r=-0.369, p<0.001)$.

Table 3

Correlations among study variables $(N=494)$

\begin{tabular}{|c|c|c|c|c|c|c|}
\hline Variables & NPQ & $\begin{array}{l}\text { SPADI pain } \\
\text { subscale }\end{array}$ & $\begin{array}{l}\text { SPADI disability } \\
\text { subscale }\end{array}$ & IPAQ & PSQI & $\begin{array}{l}\text { Health } \\
\text { perceptior }\end{array}$ \\
\hline NPQ & - & & & & & \\
\hline $\begin{array}{l}\text { SPADI pain } \\
\text { subscale }\end{array}$ & $\begin{array}{l}.418 \\
(<.001)\end{array}$ & - & & & & \\
\hline $\begin{array}{l}\text { SPADI disability } \\
\text { subscale }\end{array}$ & $\begin{array}{l}.404 \\
(<.001)\end{array}$ & $.708(<.001)$ & - & & & \\
\hline IPAQ & $\begin{array}{l}.044 \\
(.329)\end{array}$ & $.041(.361)$ & $.041(.386)$ & - & & \\
\hline PSQI & $\begin{array}{l}.253 \\
(<.001)\end{array}$ & $.404(.004)$ & $.301(<.001)$ & $\begin{array}{l}.001 \\
(.977)\end{array}$ & - & \\
\hline $\begin{array}{l}\text { Health } \\
\text { perception }\end{array}$ & $\begin{array}{l}-.326 \\
(<.001)\end{array}$ & $-.347(<.001)$ & $-.302(<.001)$ & $\begin{array}{l}.057 \\
(.208)\end{array}$ & $\begin{array}{l}-.369 \\
(<.001)\end{array}$ & - \\
\hline
\end{tabular}

\section{Factors affecting sleep quality}

Factors that affected sleep quality were pain of SPADI $(\beta=0.293, p<0.001)$, perceived difficulty of one's work $(\beta=0.111, p=0.009)$, and health perception $(\beta=-0.248, p<0.001)$. The explanatory power of the model in explaining sleep quality was $22.9 \%$ (Table 4 ). These results show that the more severe the shoulder pain and the more difficulty one perceives from their work, the worse the sleep quality and that the better the health perception, the better the sleep quality.

Table 4

Results of the stepwise multiple regression analysis for PSQI $(N=494)$

\begin{tabular}{|llll|}
\hline Variables & PSQI & & \\
\cline { 2 - 4 } & $\boldsymbol{\beta}(\mathrm{SE})$ & $\boldsymbol{t}$ & $\boldsymbol{p}$ \\
\hline Constant & $11.487(1.051)$ & 10.392 & $<0.001$ \\
\hline SPADI pain subscale & $0.293(0.005)$ & 6.634 & $<0.001$ \\
\hline Perceived physical difficulty of one's work & $0.111(0.165)$ & 2.621 & 0.009 \\
\hline Health perception & $-0.248(0.017)$ & -5.637 & $<0.001$ \\
\hline Adjusted R & 0.229 & & \\
\hline
\end{tabular}




\section{Discussion}

This study aims to provide fundamental information for nursing interventions that can improve sleep quality in middle-aged women by identifying the factors that affect sleep quality as well as the correlation between sleep quality and neck pain, shoulder pain and disability, physical activity, and health perception.

The present study showed statistically significant difference in sleep quality in relation to the general characteristics of middle-aged women, in relation to age, number of comorbidities, and the perceived physical difficulty of their work. The findings of this study suggest that sleep quality is worse with younger age. Among the participants, those with a job accounted for the most at $82.4 \%$, and most of the women in their 30s took responsibility for work, housework, and childcare, and occupational stress as well as the physical burden of housework and childcare is thought to negatively impact sleep quality. Therefore, it is necessary to plan support measures for such people by extensively assessing the occupational factors as well as the environmental and situation factors. This study found that the more comorbid diseases the participants have, the worse their sleep quality is compared to those without comorbid diseases, and the participants had various comorbid diseases, such as hypertension, diabetes, arthritis, lumbar herniated disc, neck herniated disc and cancer. This finding corroborates with various preceding studies. ${ }^{15,31-33}$ Patients with chronic low back pain are associated with poor sleep quality ${ }^{32}$ and patients with diabetes are also reported to have decreased sleep quality and sleep efficiency. ${ }^{31}$ In particular, there have been reports of decreased sleep quality in patients with diabetes being associated with symptoms such as nocturia, nocturnal hypoglycemia, and obstructive sleep apnea. ${ }^{33}$ In the case of the elderly, a higher number of chronic and comorbid diseases is associated with a higher rate of sleep disturbances and lower sleep efficiency due to persistent pain and disability. Additionally, lower sleep quality and quality of life was resulted from waking up at dawn due to night pain or having a hard time falling back asleep after having woken up once. ${ }^{15,34}$ The study is limited in that there was no comprehensive analysis of sleep quality in relation to the type of illness. Through this study, sleep quality for participants with a bigger number of comorbidities are found to be poor. Therefore, physiological health problems such as comorbidities in middle-aged women are thought to directly or indirectly affect sleep quality, which indicates that health interventions could improve not only sleep quality but also the quality of life; $31 \%$ of participants reported that their present perception of physical burden from their work is high and their sleep quality appeared to be the worst. As for women without jobs, this could be from the burden of housework and childcare and as for women with jobs, it could be from difficulty in work and job stress including burden of housework and childcare. This is consistent with a previous study that showed that compared with men, women experience burden accompanied by various changes, such as housework, childcare, work, child education, as well as hormonal changes in middle-aged women, which negatively effects sleep quality. ${ }^{35}$

The participants of this study had an average score of 8.88 (2.71) in sleep quality and $89.7 \%$ of the participants were classified as a poor sleeper with a score of $>5$. The result is similar to other studies that examined sleep quality in middle-aged women and obtained a score of $8.4^{22,36}$ and is higher than the 
score of 7.76 obtained in another study conducted on middle-aged women. ${ }^{37}$ This result implies that sleep disorders among South Korean middle-aged women are common. South Korean middle-aged women have the tendency to ignore their sleep management. This could be attributed to them dismissing it as a menopausal symptom experienced in midlife or the result of neglecting one's health and caring only for the health of the family and sacrificing for the family despite the poor health conditions subjectively felt due to the burden of childcare, housework and workplace stress. Therefore, the result of this study suggests that active interests and efforts are needed to provide health information or develop health education and sleep intervention programs to improve the sleep quality in middle-aged women of South Korean society where interest toward their sleep health is low.

Regarding the correlation between sleep quality and related variables, the present study showed positive correlation between sleep quality and neck pain and shoulder pain and disability and a negative correlation between sleep quality and health perception. As such, the more severe the neck pain and shoulder pain and disability, the higher the score for sleep quality, demonstrating a poor quality of sleep. The higher the self-health perception was, the lower the sleep quality score, hence demonstrating good sleep quality. This corroborates with previous studies ${ }^{38,39}$ that show the more severe the neck pain, the more severe the shoulder pain, and the more severe the shoulder pain, the more severe the shoulder disability and that such symptoms or disabilities worsen sleep quality. ${ }^{40}$ Women complain of chronic pain as they spend more time making repetitive movements in the same posture for a long time due to work or house chores. Since these pains negatively affect sleep quality due to the accompanying muscle dysfunction, it seems necessary to establish an intervention that can fundamentally improve health promotion through investigating their lifestyle and postures in daily life according to the area of chronic pain.

In the study's findings, shoulder pain, perceived difficulty of one's work, and health perception were analyzed as significant factors that affect sleep quality in middle-aged women. Similar results were obtained in a study by Bintang et al ${ }^{41}$ and Lee and $\mathrm{Oh}^{15}$ in which pain affected sleep quality and a more severe pain resulted in a higher sleep quality, supporting this study's findings. Moreover, the perceived difficulty of one's work can be affected by various factors, such as occupation, house chores, childcare and health concerns, and such factors can consequently affect one's health perception and further worsen sleep quality. ${ }^{41}$ This study found no correlation between sleep quality and physical activity, and this corresponds to previous studies that also found that the level of women's physical activity has no impact on sleep quality. ${ }^{42}$ In other words, this study found that the participants' physiological symptoms, physical burden and health perceptions were more important factors in sleep quality than physical activity.

This study has some limitations. The first is that the subject of the study were South Korean middle-aged women who resided in Seoul; hence, the results cannot be generalized to other populations. Second, because the sleep quality in middle-aged women was assessed using self-report tools, it is different from identifying the actual sleep pattern. Lastly, this study is a cross-sectional study; hence, it is limited in that 
the cause and effect in between variables cannot be analyzed in various ways. Despite these limitations, in consideration of the study's findings, middle-aged women's shoulder pain, perceived difficulty of one's work and health perception were found to be important factors in determining sleep quality. These results suggest that the severe physical symptoms of shoulder pain, which the middle-aged women complain of, can negatively affect sleep quality and that an intervention of sleep quality in consideration of such physical symptoms is needed. Based on the results of this study, to improve sleep quality in middle-aged women, healthcare workers should take into consideration the subject's health and other symptoms or pain. Because perceived difficulty of one's job and health can affect sleep quality, it is necessary to develop a health intervention strategy to provide healthcare for physical health, as well as mental and social support to lessen the burden of work, house chores and childcare to improve health promotion. For a follow-up study, based on the results of previous studies that show physical symptoms affect sleep quality and such physical symptoms not only affect individual physiological health but also mental health ${ }^{15,43}$ and the results of the present study, nurses in clinical practice should plan and provide health education and nursing intervention that enhances sleep quality in middle-aged women to ultimately improve their physical and mental quality of life. This should be done based on objectively measured data of the sleeping state, while taking into consideration their physiological symptoms in relation to their comorbidities and age.

\section{Conclusions}

This study identified the correlation between sleep quality and neck pain, shoulder pain and disability, physical activity, and health perception and analyzed the factors that affect sleep quality. Moreover, there was a difference in sleep quality depending on the age, number of comorbidities and the perceived difficulty of one's work. As a result of analyzing the factors that affect sleep quality, shoulder pain, perceived difficulty of one's work, and health perception variables had $22.9 \%$ explanatory power in explaining sleep quality. From these results, the following is suggested. By analyzing the difference in sleep quality according to the pain and comorbid diseases based on middle-aged women's physical health, sleep education and health intervention are needed to improve sleep quality by objectively analyzing the difference in sleep quality in relation to the subject's physical health and symptoms.

\section{List Of Abbreviations}

IPAQ International Physical Activity Questionnaire

MPA Moderate physical activity

NPQ Neck Pain Questionnaire

PSQI Pittsburgh Sleep Quality Index

SPADI Shoulder Pain and Disability Index 
VPA Vigorous physical activity

\section{Declarations}

Informed consent was obtained from all subjects.

\section{Ethics approval and informed consent}

Ethical issues related to the present study were considered and approved by the Research Committee of Daejeon University (1040647-202103-HR-006-02).

\section{Consent for publication}

Not applicable.

\section{Availability of data and materials}

The data presented in this study are available on request from the corresponding author. The data are not publicly available owing to privacy.

\section{Competing interests}

The authors declare that they have no competing interests.

\section{Funding}

This research was funded by the National Research Foundation of Korea (NRF) grant funded by the Korea government Ministry of Science and ICT (MSIT), grant number 2020R1C1C1015358.

\section{Authors' contributions}

Conceptualization, J.O.; methodology, M.K.L.; software, M.K.L.; validation, J.O.; formal analysis, J.O.; investigation, J.O.; resources, M.K.L.; data curation, M.K.L.; writing-original draft preparation, M.K.L. and J.O.; writing-review and editing, M.K.L. and J.O.; visualization, J.O.; supervision, M.K.L.; project administration, J.O. All authors have read and agreed to the published version of the manuscript.

\section{Acknowledgments}

Not applicable

\section{References}

1. Hadamus A, Wojda A, Białoszewski D. Can the sleep quality of patients with chronic neck pain be improved by muscle energy techniques combined with Swedish massage? Complement Ther Clin Pract. 2021;44:101421. 
2. Luime JJ, Koes BW, Hendriksen IJ, Burdorf A, Verhagen AP, Miedema HS, et al. Prevalence and incidence of shoulder pain in the general population; a systematic review. Scand J Rheumatol. 2004;33:73-81.

3. Alavinia SM, Molenaar D, Burdorf A. Productivity loss in the workforce: associations with health, work demands, and individual characteristics. Am J Ind Med. 2009;52:49-56.

4. Leijten FR, van den Heuvel SG, Ybema JF, van der Beek AJ, Robroek SJ, Burdorf A. The influence of chronic health problems on work ability and productivity at work: a longitudinal study among older employees. Scand J Work Environ Health. 2014;40:473-82.

5. Gould R, Ilmarinen J, Järvisalo J, Koskinen S. Dimensions of work ability: results of the Health 2000 Survey; 2008.

6. Tsai SP, Bhojani FA, Wendt JK. Risk factors for illness absence due to musculoskeletal disorders in a 4-year prospective study of a petroleum-manufacturing population. J Occup Environ Med. 2011;53:434-40.

7. Duman M, Timur Taşhan S. The effect of sleep hygiene education and relaxation exercises on insomnia among postmenopausal women: A randomized clinical trial. Int J Nurs Pract. 2018;24:e12650.

8. Young DR, Sidell MA, Grandner MA, Koebnick C, Troxel W. Dietary behaviors and poor sleep quality among young adult women: watch that sugary caffeine! Sleep Health. 2020;6:214-9.

9. Swanson CM, Kohrt WM, Buxton OM, Everson CA, Wright Jr KP, Orwoll ES, et al. The importance of the circadian system \& sleep for bone health. Metabolism. 2018;84:28-43.

10. Oh, H. Effect of perceived health status and sleep quality on health-related life quality among elderly Pilates participants. Korean J. Sport Sci.2016;25:125-37.

11. Rosenstock IM. The Health Belief Model: explaining health behavior through experiences. 1990;3963.

12. Li J, Yang B, Varrasse M, Ji X, Wu M, Li M, Li K. Physical activity in relation to sleep among community-dwelling older adults in China. J Aging Phys Act. 2018;26:647-54.

13. Hwang Y, Oh J. Factors affecting health-promoting behaviors among nursing students. Int J Environ Res Public Health. 2020;17:6291.

14. Jung G, Oh J. The relationship between childhood trauma, eating disorders, and sleep quality among registered hospital nurses in South Korea. Healthcare (Basel). 2020;8:490.

15. Lee MK, Oh J. Health-related quality of life in older adults: Its association with health literacy, selfefficacy, social support, and health-promoting behavior. Healthcare (Basel). 2020;8:407.

16. Jeong SW, Kim SH, Kang SH, Kim HJ, Yoon CH, Youn TJ, et al. Mortality reduction with physical activity in patients with and without cardiovascular disease. Eur Heart J. 2019;40:3547-55.

17. Kadariya S, Aro A. Barriers and facilitators to physical activity among urban residents with diabetes in Nepal. PLoS One. 2018;13(6):e0199329. 
18. Lee IM, Shiroma EJ, Lobelo F, Puska P, Blair SN, Katzmarzyk PT, et al. Effect of physical inactivity on major non-communicable diseases worldwide: an analysis of burden of disease and life expectancy. Lancet. 2012;380:219-29.

19. Carneiro-Barrera A, Amaro-Gahete FJ, Acosta FM, Ruiz JR. Body composition impact on sleep in young adults: The mediating role of sedentariness, physical activity, and diet. J Clin Med. 2020;9:1560.

20. Štefan L, Sporiš G, Krističević T, Knjaz DJ. Associations between sleep quality and its domains and insufficient physical activity in a large sample of Croatian young adults: A cross-sectional study. BMJ Open. 2018;8:e021902.

21. Park Y-J, Kim Y-S. A convergence study of depression, health-related quality of life and sleep disturbance according to the level of physical activity of hemodialysis patients. J Digit Converg. 2018;16:345-55.

22. Sternfeld B, Guthrie KA, Ensrud KE, LaCroix AZ, Larson JC, Dunn AL, et al. Efficacy of exercise for menopausal symptoms: a randomized controlled trial. Menopause. 2014;21:330-8.

23. Buysse DJ, Reynolds CF, Monk TH, Berman SR, Kupfer DJ. The Pittsburgh Sleep Quality Index: a new instrument for psychiatric practice and research. Psychiatry Res. 1989;28:193-213.

24. Roach KE, Budiman-Mak E, Songsiridej N, Lertratanakul Y. Development of a shoulder pain and disability index. Arthritis Care Res. 1991;4:143-9.

25. Breckenridge JD, McAuley JH. Shoulder pain and disability index (SPADI). J Physiother. 2011;57:197.

26. Leak AM, Cooper J, Dyer S, Williams KA, Turner-Stokes L, Frank AO. The Northwick Park Neck Pain Questionnaire, devised to measure neck pain and disability. Br J Rheumatol. 1994;33:469-74.

27. Lee K-W, Seo H-D, Jung K-S, Kim S-H, Chung Y-J. Reliability and validity of Korean version Northwick Park Neck Pain Questionnaire in neck pain patients. Phys Ther Korea. 2010;17:68-76.

28. Ware JE Jr. Scales for measuring general health perceptions. Health Serv Res. 1976;11(4):396-415.

29. Lee TH. Determinants of health promotion behavior: centered on well adults living in Seoul [Master's thesis]. Yonsei University; 1990.

30. Ku HJ, Lee DT. Estimation of physical activity levels using International Physical Activity Questionnaires (IPAQ) in Korean college students. J. Sports Sci. 2016;24:65-73.

31. Budhiraja R, Roth T, Hudgel DW, Budhiraja P, Drake CL. Prevalence and polysomnographic correlates of insomnia comorbid with medical disorders. Sleep. 2011;34:859-67.

32. Gerhart JI, Burns JW, Post KM, Smith DA, Porter LS, Burgess HJ, et al. Relationships between sleep quality and pain-related factors for people with chronic low back pain: tests of reciprocal and time of day effects. Ann Behav Med. 2017;51:365-75.

33. Surani S, Brito V, Surani A, Ghamande S. Effect of diabetes mellitus on sleep quality. World J Diabetes. 2015;6:868.

34. Parmelee PA, Cox BS, DeCaro JA, Keefe FJ, Smith DM. Racial/ethnic differences in sleep quality among older adults with osteoarthritis. Sleep Health. 2017;3:163-9. 
35. Kim GU, Park S, Kim S. Functional health in Korean middle-aged women with poor sleep quality. Int J Nurs Knowl. 2020;31:232-9.

36. Newton KM, Reed SD, Guthrie KA, Sherman KJ, Booth-LaForce C, Caan B, et al. Efficacy of yoga for vasomotor symptoms: a randomized controlled trial. Menopause. 2014;21:339-46.

37. Serrano-Guzmán M, Valenza-Peña CM, Serrano-Guzmán C, Aguilar-Ferrándiz E, Valenza-Demet G, Villaverde-Gutiérrez CJ. Effects of a dance therapy programme on quality of life, sleep and blood pressure in middle-aged women: A randomised controlled trial. Med Clin (Barc). 2016;147:334-9.

38. Libardoni TC, Armijo-Olivo S, Bevilaqua-Grossi D, de Oliveira AS. Relationship between intensity of neck pain and disability and shoulder pain and disability in individuals with subacromial impingement symptoms: A cross-sectional study. J Manipulative Physiol Ther. 2020;43:691-9.

39. Park S-Y, Choi T-S, Kim D-H, Ryu B-H, Lee S-B. Correlation between neck and shoulder pain, neck and shoulder disability, headache and smartphone addiction in adults with sleep disorders. KSPM. 2020;15:43-50.

40. Lee MK, Oh JH. The relationship between pain and physical function: Mediating role of sleep quality, depression, and fatigue. J Gerontol Nurs. 2019;45:46-54.

41. Bintang AK, Santosa I, Goysal Y, Akbar M, Aulina SJ. Relationship between sleep quality and pain intensity in patients with chronic low back pain. Med Clin Pract. 2012;4:100208.

42. Wu J, Einerson B, Shaw JM, Nygaard IE, Sheng X, Wolpern A, et al. Association between sleep quality and physical activity in postpartum women. Sleep Health. 2019;5:598-605.

43. Guo G, Fu T, Yin R, Zhang L, Zhang Q, Xia Y, et al. Sleep quality in Chinese patients with rheumatoid arthritis: contributing factors and effects on health-related quality of life. Health Qual Life Outcomes. 2016;14:1-8. 